\title{
Code Mixing On Facebook Among Malaysian Tesl Students
}

\author{
Huzaina Abdul Halim \\ University of Malaya \\ huzaina@um.edu.my \\ Hana Nadia Ahmad Nadri \\ University of Malaya \\ nad5058@siswa.um.edu.my \\ Foziah Mahmood \\ University of Malaya \\ foziahm@um.edu.my
}

\begin{abstract}
Facebook which is one of the popular social networking sites has become a medium of communication and interaction for its users. This site popularity has aroused the researcher's interest to choose it as a ground for this study. It has been identified that there is less study has been conducted particularly on the internet-based written texts Malaysia (Azirah, Norizah\& Philip, 2012). The findings of this study have been believed would contribute and add to the literature in terms of code-mixing and education context since the participants were from TESL community. Data analysis would be based on the observation, Facebook status and wall interaction and lastly online openended questionnaire. The obtained data was analysed using the observation checklist, a tally sheet, as well as adapted and integrated frameworks by Ratna (2007) and Hoffman (1991) and also by Saville-Troike (2003) and Holmes (2001) for the reasons of code-mixing. Findings discovered that phrase insertion was the most frequent inserted level of code-mixing in Facebook while showing solidarity was the main reason of codemixing in Facebook. This study which mainly focus on the participants' way of communication in Facebook would be another root for other researchers to extend this kind of study henceforth focuses on other vital components of code-mixing that may persist when someone code-mixing in Facebook.
\end{abstract}

Keywords: code-mixing, Facebook, social networking.

\section{INTRODUCTION}

English which has become the most important foreign language in many parts of the world has been widely used too in other vital areas such as medical, dental, legal, business and communication (Norhana, 2008). In terms of communication, someone is not restricted to use this language only at home and school but also can use it to communicate and socialize with one another (Wong \&Thambyrajah, 1991).

\section{Research Problem}

Due to the existence of the two languages and there is an identification in having a good command in those languages; Malaysians are classified as a part of bilinguals (Spolsky, 1998). The ability to communicate in both languages likely gives Malaysians an option to communicate in any language that they are comfortable with. Hence, it is not surprising to hear a family converse in a different language when they are communicating with peers or 
colleagues (Karchner-Ober, 2012). Hence, a speaker may code-mix the speaking language specifically the first language with the second language in a daily communication.

Code-mix is believed not only exist in conversation but also may occur in written form likewise in Facebook: this famous social networking site is one of the communication tools for the educators and the students (Madge, Meek, Wellens, \& Hooley, 2009). Specifically, pertaining to this study focus, Facebook can be a platform for the teachers and tutors to communicate and interact with each other as well as with the other Facebook users. They may also code-mix in Facebook since there are seventy languages which are available and can be used in such site (Saleem, Yi-hsuan\&Kanni, 2014). Additionally, the type of communication in Facebook which was seen fun and not serious (Lewis \&West,2009) is like allowing the participants to code-mix in Facebook.

\section{Research Questions}

This study is designed to answer the following research questions:

1. What is the level of code-mix used by TESL graduates in Facebook?

2. Which level of code-mix is frequently used by TESL graduates?

3. Why do TESL graduates code-mix in Facebook?

\section{Review of the literature}

Norhana (2008) identified bilingualism as a speaker's ability to be competent either in a second language or other languages instead of the mother tongue. Harding-Esch and Riley (2003) regard a bilingual as someone who speaks two languages perfectly. On the other hand, Siguan and Mackey (2009) refer bilingualism as those who simultaneous alter two mastered languages. Extending this view, it can be said that bilinguals are at least proficient in two languages. These bilinguals are believed would be able to use any of the mastered language equally in any situations. It also can be simplified that bilinguals have a balance in two language systems.

The presence of three main ethnic groups in Malaysia known as Malays, Chinese and Indians (Gaudart, 2003) cause the existence and exposure to various languages. Pertaining to the plurality of community in this country, Malaysians are believed know more than one language (Kamila, 2010).Hence, Malaysians can be considered as bilinguals since most of them comprehend two languages; mother tongue language and English language. According to Dias (2011), since bilinguals are free to use any of the competent languages, there will be a state which will lead bilinguals to code-mix during interactions. Even though bilinguals are free to converse in any languages, they should be able to distinguish what type of language is appropriate to be used either in a formal or informal situation.

Grosjean (2001) views code-switching as a complete shift to another language in terms of word, phrase or sentence. This scholar thinks that bilinguals use a base language and activate other competent language from time to time to code-switch. In other words, bilinguals are seen would be able to switch from the first language into another language particularly the second most competent language.

From a general scope, Kachru and Nelson (2006) besides Bonvillian (1993) examine both code-mixing and code-switching as common strategies for communication. Low and Dan (2006) find code-mix is likely been used in a bilingual society. Adding further support, Woon (2007) states it is common for a particular society to code-mix when two or more languages exist. 
The adapted and integrated frameworks on the level of code-mix by Ratna (2007) and Hoffman (1991) will be used in order to justify which level of code-mix is regularly being used by the selected participants when they are posting their Facebook status and interacting on the Facebook wall. Saville-Troike's (2003) and Holmes's (2001) frameworks also will be integrated as a reference to identify the possible reasons for code-mixing in Facebook.

\section{METHODOLOGY}

This study will be qualitative in nature. To be specific, this study can be classified as a case study. It attempts to indicate the level of code-mix. The researcher at first will identify seven levels of code-mix namely word insertion, phrase insertion, clause insertion, sentence insertion, idiom or expression insertion, hybrid insertion, reduplication insertion and lastly change in pronunciation. Besides, there also will be identification on the most used code-mix level in Facebook. This study will also give a descriptive analysis on the reasons for codemixing in Facebook.

The study design was chosen because it can give in-depth understanding on certain phenomena (Merriam, 2009). In terms of sample selection, the researcher has a power to choose the sample of this study. It would be purposely and intentionally chosen participants. All Malay teachers and tutors who comprehend both Malay and English languages will be chosen. This kind of sampling is in line with this case study and the researcher's intention which is to gain in-depth understanding of a particular situation (Merriam, 2009).

The participants who have undergone the TESL (Teaching English as a Second Language) program and have graduated from a private university will be selected. At present, these participants are holding posts as teachers and tutors. Both male and female participants will be chosen after identification on code-mix in Facebook particularly on the posted status and wall interaction. The following instruments will be utilized in data collection:

1. Observation checklist

2. Tally sheet (level of code-mix)

3. Open-ended Online Questionnaire

\section{DATA ANALYSIS}

Data collection in this study is would be varied, thus in-depth understanding on code-mix phenomenon could be gained. Data will be gathered through observations, pictures (Facebook status and wall interaction) and online questionnaires. Since there were factual data (Facebook status and wall interaction) together with observations and questionnaires, a triangulation of multiple methods will exist. This method thus may provide a descriptive analysis and insights into this study.

The adapted and integrated frameworks on the level of code-mix by Ratna (2007) and Hoffman (1991) will be used in order to justify which level of code-mix is regularly being used by the selected participants when they are posting their Facebook status and interacting on the Facebook wall. Saville-Troike's (2003) and Holmes's (2001) frameworks also will be integrated as a reference to identify the possible reasons for code-mixing in Facebook.

\section{FINDINGS}

Based on the findings, it was found that participants code-mix at different levels. In reference to this matter, there were participants who code-mix at the same two levels of code-mix. In this 
study, the highest usage level of code-mix was phrase insertion. This might be because writing a phrase in English is still understandable for the readers although it only comprises of two words. There were few similar phrases identified in the posted Facebook statuses. The phrases are 'Thank you, Congrats to..., Happy for you and Happy birthday'. In contrast with this code-mix level, idiom or expression insertion was the least used code-mix level by the participants. Perhaps, this might be due to the inexistence of the same type of idiom (which brings the similar meaning) in Malay language.

\section{Analysis on Level of Code-mixing \\ Example 1: Word Insertion}

Anis Amira at Wadihana Islamic Steakhouse, Seksyen 7 , Shah
Alam, Selangor
12 July - Instagram - $\mathbb{4}$
Iftar with Kak Natrah!

This Facebook status is an example of code-mix which occurred at word insertion level. The word 'with' was English inserted word.

\section{Example 2: Involving a change of pronunciation}

Ilyani Rahman
Juz wanuary - Instagram - 24
Ju show ma 2 gojes dimples....

This Facebook status involved a change of pronunciation. The word 'gojes' derived from the word gorgeous which means very beautiful. This status was categorized into this level when the word 'gorgeous' was pronounced or changed into Bahasa Melayu phonological way of pronunciation.

Table 1: Summary of Level of Code-Mixing and Frequency of Code-Mixing

\begin{tabular}{|c|c|c|}
\hline Level of Code-mixing & Frequency & Percentage $(\%)$ \\
\hline Word insertion & 14 & $23.33 \%$ \\
\hline Phrase insertion & 34 & $56.67 \%$ \\
\hline Clause insertion & 6 & $10 \%$ \\
\hline Idiom or expression insertion & 1 & $1.67 \%$ \\
\hline Hybrid insertion & 3 & $5 \%$ \\
\hline Reduplication insertion & 0 & 0 \\
\hline Involving a change of pronunciation & 2 & $3.33 \%$ \\
\hline \multicolumn{3}{|c|}{$\begin{array}{l}\text { On the other hand, pertaining to another researcher's concern on the reasons of code-mixing, } \\
\text { showing solidarity was identified as the most preferred reason by the respondents. They used } \\
\text { code-mix might be because they wanted to signify that they belong to the same ethnic group of } \\
\text { other Facebook users. On the contrary, the least preferred reason was to exclude other people } \\
\text { when a comment is intended for a limited audience. This reason might be referred to the }\end{array}$} \\
\hline
\end{tabular}


posted statuses which most of the posted status was written in general and the participants did not mention or tag other Facebook users.

Generally, pertaining to the obtained reasons for code-mix, the participants who responded to the online questionnaire have pointed a number of reasons for code-mix in Facebook. It seemed code-mix is necessary and useful for interacting and communicating with other Facebook users. Although code-mix may not be the right way of communication especially for the tutors and teachers, it has its own specialty in communication. For instance, when someone is using one language for expression and find it less expressive, he or she can code-mix if it is better for delivering an expressive message. Another example can be noted when a group of people share the same background like what has been mentioned by a respondent in the questionnaire (e.g., a group of people who have the same schemata on the second language). These people might code-mix back and forth as they know they have the same language background thus could understand each other's way of communication.

To be specific, the most frequent reason that has been stated by the respondents was to show solidarity. The participants might think a good rapport could be established by code-mixing in Facebook among other bilinguals and those who were from the same ethnic group. Besides, they might think by code-mixing, they were fit to be in a particular group and belong to the same ethnic group specifically the bilinguals in Facebook. Those participants also might find code-mix helpful in easing communication and interaction with close people such as friends and family.

Affection and for real lexical need as the second-most preferred reasons followed closely behind. As for the affection reason, the Facebook users might use Facebook as it is a popular and a common medium of communication nowadays to express thoughts or feelings. They might think feelings such as anger, sadness and happiness were better expressed if they use Facebook coherence with code-mixing. This is in line with what Khe and Wing (2012) have mentioned about the Facebook status in which it could be used to express thoughts as well as moods of the Facebook users.

Another second-most preferred reason was for real lexical need. Since the respondents are all tutors and teachers, the researcher personally believes and would not have a doubt on their proficiency and competency in English language even though they used to code-mix in Facebook. This is might due to one particular time or situation where they have a difficulty in finding the exact word in another language. Furthermore, there must be a spontaneous moment where a bilingual could only think of an English word instead of Malay word. Other than that, the use of English word might due to the suitability of a context which it might be easier and better to be used. The examples of words for this kind of situation are "Breakfast, lunch, yummy, princess" and "game".

The least preferred reason identified in the finding was to exclude other people when a comment is intended for only a limited audience. This reason could be referred to the participants' privacy or in other words they do not want anyone not mentioned (in the Facebook status) to interfere with his or her interaction. This reason also refers to a status or wall interaction which is solely for someone or a certain group of people.

The remaining reasons -- to soften or strengthen request or command, to reflect social status, topic and to persuade audience -- were not mentioned by any of the respondents. Other than 
that, data analysis shows that more than ten reasons stated by participants were not aligned with the framework of this study. The given reasons included spoken language influence, incompetency, for learning aid, social norm, spontaneity, language suitability, one language is less expressive, convey clear message, for comfort, for better understanding, ease of communication, setting and lastly for lively and expressive conversation. Since these reasons were not in the framework of this study, the researcher has decided not to analyze them further. However, future researchers who intend to conduct a close study are recommended to use these reasons as a framework in their study.

\section{CONCLUSION}

The findings of this study are enlightening for the researcher. It portrays code-mix was applied in Facebook even by the tutors and teachers. The findings show different level of code-mix which was applied by the participants as well as the frequency of code-mix level. This study also reveals the possible reasons for code-mixing in Facebook which was also obtained from the participants of this study. It can be concluded that code-mix in Facebook is widely been used and practiced by the bilinguals as well as the tutors and teachers. Some people might not be aware of code-mix occurrence and others might think it is just an act of spontaneity as mentioned by the two respondents in the questionnaire. They might not realize when they code-mix in Facebook as it has become a social norm when they use code-mix to post a status or interact with other users.

In short, the use of code-mix in Facebook might be found as a common or normal situation in a multilingual country. The researcher personally believes it is normal for anyone to code-mix in Facebook thus any doubt or negative perspective on someone's language proficiency should not arise. On the other hand, the users' attitude is the most important thing. As long as the users know the formality context and know when code-mix should and should not be applied, it surely would not be a serious case for them to code-mix. Bearing in mind that they are aware of formal and informal context too, it is believed that they will not apply code-mix when they are in a formal situation.

\section{References}

Azirah Hashim, Norizah Hassan, \& Phillip, A. S. (2012). Language use in the construction of interpersonal relationships: electronic English in Malaysia. In E.-L. Low \& A. Hashim (Eds.), Varieties of English in Southeast Asia: Feature, policy and language in use (pp. 325-341). Amsterdam, The Netherlands: John Benjamins.

Bonvillian, N. (1993). Language, culture, and communication: The meaning of messages. Englewood Cliffs, NJ: Prentice Hall.

Gaudart, H. (2003).English language teaching process.Petaling Jaya, Malaysia: Sasbadi.

Grosjean, F. (2001). The Bilingual's Language Modes. In J. L. Nicol (Ed.), On mind, two languages: Bilingual language processing (pp. 1-22). Cambridge: MA: Blackwell.

Harding-Esch, E., \& Riley, P. (2003).The bilingual family: A handbook for parents. Cambridge, UK: Cambridge University Press.

Hoffman, C. (1991). An introduction to bilingualism. New York: Longman.

Holmes, J. (2001). An introduction to sociolinguistics (2nd ed.). Harlow, UK: Longman.

Kachru, Y., \& Nelson, C. L. (2006).World Englishes in Asian contexts. Hong Kong: Hong Kong University Press.

Kamila Ghazali. (2010). National identity and minority languages.What is the United Nations Academic Impact? Retrieved from

http://wwwupdate.un.org/wcm/content/site/chronicle/home/archive/issues2010/un_academic_impact/nation al_identity_and_minority_languages

Karchner-Ober, R. (2012). Speaking, reading and writing in three languages. 
Preferences and attitudes of multilingual Malaysian students.International Journal of Multilingualism, 9(4), 385406. doi: 10.1080/14790718.2012.714382

Khe, F. H., \& Wing, S. C. (2012). Use of Facebook: A Case Study of Singapore Students' Experience. Asia Pacific Journal of Education, 32(2), 181-196.doi: 10.1080/02188791.2012.685560

Low, W. W-M., \& Dan, L. (2006). Persistent Use of Mixed Code: An Exploration of Its Functions in Hong Kong Schools. International Journal of Bilingual Education and Bilingualism, 9(2), 181-204. doi: 10.1080/13670050608668640

Merriam, S. B. (2009). Qualitative research: A guide to design and implementation(2nd ed.). San Francisco, CA: Jossey-Bass.

Norhana Abdullah. (2008). Reaffirming Priorities: The Roles of Bahasa Melayu and English in Malaysia. In Haliza Harun, Issues on English as second language pedagogy: A research based perspective (pp. 119-131).Negeri Sembilan, Malaysia: UniversitiSains Islam Malaysia.

RatnaMaulidini. (2007). Campurkodesebagaistrategikomunikasi customer service (Master's thesis, UniversitasDiponegoro). Retrieved from http://eprints.undip.ac.id/5344/1/SKRIPSI.pdf

SaleemAlhabash., Yi-hsuan, C., Kanni, H. (2014). MAM \& U\&G in Taiwan: Differences in the uses and gratifications of Facebook as a function of motivational reactivity. Computers in Human Behavior, 35, 423-430. doi: 10.1016/j.chb.2014.03.033

Saville-Troike, M. (2003).The ethnography of communication: An introduction (3rd ed.). Malden, MA: Blackwell Publishing.

Siguan, M., \& Mackey, W. F. (2009).Education and bilingualism. London, UK: Kogan Page.

Spolsky, B. (1998). Sociolinguistics. Oxford, UK: Oxford University Press.

Wong, I. F. H., \&Thambyrajah, H. (1991). The Malaysian Sociolinguistic situation: An overview. In A. Kwan-Terry (Eds.), Child Language Development in Singapore and Malaysia (pp. 3-11). Singapore: Singapore University Press. Retrieved from

http://books.google.com.my/books?hl=en\&lr=\&id=zMLy36DCCasC\&oi=fnd\&pg=PA3\&dq=The+Malaysian+Socioli nguistic+situation+an+overview\&ots=BMz_oeaKwH\&sig=-

3GtabAVR3ud065v3BcorYqHK_k\#v=onepage\&q=The\%20Malaysian\%20Sociolinguistic\%20situation\%20an\%20o verview\&f=false

Woon, J. Y. H. (2007). Code-mixing: Linguistic Form and Socio-cultural Meaning. The International Journal of Language Society and Culture, 21, 1-8. Retrieved from

http://www.educ.utas.edu.au/users/tle/Journal/issues/2007/21-2.pdf 